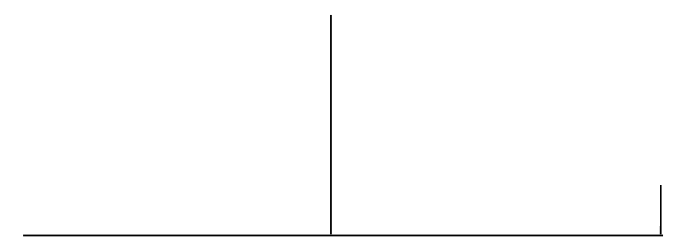

Rev. Latinoam. Psicopat. Fund., São Paulo, v. 15, n. 3, p. 497-511, setembro 2012

\title{
Pesimismo freudiano: salud mental y malestar en la cultura
}

\author{
F. Manuel Montalbán-Peregrín
}

Las relaciones entre el psicoanálisis y el pensamiento social hunden sus raíces en los primeros desarrollos del descubrimiento freudiano. El propio Freud no es ajeno a esta cuestión y después de la Primera Guerra Mundial dedica una parte significativa de su producción a los llamados textos sociológicos. Tanto la teoría social como la concepción pulsional en sus últimas elaboraciones representan el equipaje más comprometedor de la herencia freudiana, que sólo algunos autores como Jacques Lacan están dispuestos a retornar. El llamado pesimismo freudiano asociado a estos textos critica la lectura optimista de la metáfora poder-expresión que establece la acción unilateral del poder sobre algo que queda imposibilitado de expresarse libremente. Es desde estas coordenadas que pretendemos adentrarnos en la concepción freudiana de salud mental. El hecho de que la ley no sea tan enemiga de la pulsión, que la ley no esté depurada de la satisfacción patológica, tendrá importantes efectos para la retórica de la liberación personal y política.

Palabras clave: Freud, psicoanálisis, pesimismo freudiano, malestar en la cultura 


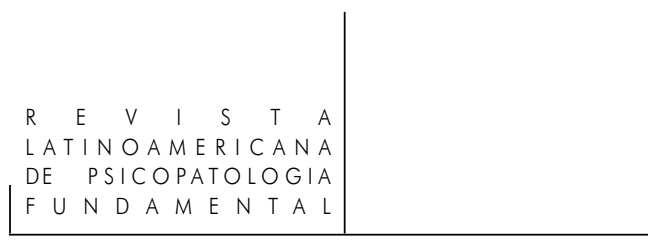

\section{Introducción}

El contacto, con desigual resultado, entre el hallazgo del inconsciente freudiano y la construcción teórica de la experiencia de lo colectivo se produce también desde momentos tempranos. La deriva jungiana, la recepción crítica de los textos freudianos efectuada por el círculo de Bajtin desde la perspectiva marxista, o la lectura que del psicoanálisis realiza la primera generación de la Escuela de Frankfurt, son ejemplos con identidad e implicaciones importantes. El propio Freud no es ajeno a esta tensión y después de la Primera Guerra Mundial dedica una parte significativa de su producción a los llamados textos sociológicos o antropológicos. Tanto la teoría social como la concepción pulsional en sus últimas elaboraciones representan el equipaje más comprometedor de la herencia freudiana que en la emigración hacia Norteamérica los psicoanalistas suelen dejar en tierra. No es una coincidencia azarosa. Pulsión de muerte y vínculo social establecen en la obra de Freud una relación ciertamente paradojal, en muchas ocasiones ingenuamente simplificada. En su movimiento de "retorno a Freud", Jacques Lacan se hará cargo, entre otras cuestiones, de estas valijas olvidadas por la tradición postfreudiana.

No obstante es necesario reconocer que ha sido mayoritaria la aproximación al inconsciente desde una óptica individualista. De hecho, la mayoría de las críticas pretendidamente sociológicas vertidas sobre el psicoanálisis se han basado en la supuesta tendencia individualizante de la vida psíquica. Como comprobamos, las dificultades genéricas en la historia del pensamiento para articular lo particular y lo universal se reproducen una vez más. El uno por uno de la cura psicoanalítica que pone en juego la lógica inconsciente condiciona, a veces de manera excesiva, la reserva del psicoanálisis hacia el hecho social, y puede introducir una cierta indiferencia, si no cinismo, hacia la escena colectiva y sus dilemas más evidentes. Es más, la propia comunidad psicoanalítica, puesto que desde sus inicios el psicoanálisis vinculó, 
con más o menos dificultades, a sus practicantes, ha recurrido, como cualquier grupo humano, al refugio de lo colectivo, al goce de la lengua común, frente a los avatares de la época: comunidad como pantalla del acontecer social. En las últimas décadas, sin embargo, se realizan acercamientos al psicoanálisis desde las ciencias humanas, centrados en la cuestión social y sus múltiples derivaciones, que en muchas ocasiones sorprenden incluso al propio psicoanálisis. Ciertamente existen contextos más predispuestos que otros para generar este tipo de aproximaciones, cuando no verdaderas apropiaciones. Este es el caso del campo de las ciencias sociales que se afanan en reconstruir la teoría social a partir de la irrupción postmoderna. El desarrollo de tendencias del conocimiento que entienden tanto la realidad social y cultural cuanto las propias ciencias sociales como construcciones lingüísticas, acciones retóricas, ha posibilitado que, en lo que algunos se obstinan en llamar espejismos de fin de siglo, se diluyan ciertas fronteras academicistas y se promuevan acercamientos y confluencias más o menos creativas alrededor de las ideas de pluralismo, heterogeneidad o diferencia. Es en este contexto que el psicoanálisis, la disciplina del "otro reprimido" como la ha calificado Parker (1996), entra en un nuevo debate con la psico(socio)logía, la teoría política y la teoría crítica.

Sin lugar a dudas, la presencia y enseñanza de Jacques Lacan en el panorama cultural francés de la segunda mitad del pasado siglo ha actuado como catalizador de muchos de estos encuentros. Pero en este tipo de operaciones se corre el riesgo de asimilar el psicoanálisis con cualquier otro instrumento científico dentro de la multiplicidad técnica pret-a-porter. El contacto entonces entre la ciencia social heterodoxa y el psicoanálisis, en general, y la enseñanza lacaniana, en particular, se ha producido gradual pero inevitablemente. Junto a Foucault, Derrida, Habermas, Lyotard etc., Lacan se incorpora también, a veces en un cóctel indigesto, al universo iconográfico de la teoría social contemporánea.

En este escenario epistémico, uno de los resultados más interesantes de la llamada crisis de la psicosociología en las dos décadas finales del siglo XX ha sido una osmosis de ideas y planteamientos heterogéneos hacia el interior de la disciplina con clara vocación crítica. El psicoanálisis, sobre todo en la matriz freudo-lacaniana, ha despertado un renacido interés en el construccionismo social, en general, y en la aproximación discursiva, en particular. Parker (1991) llega a realizar la afirmación de que el psicoanálisis podría ser tomado como una fuente de la psicología social radical, la materia prima para algo que podría ocupar el espacio actual de la psicología social. Por su parte, Billig (2006) aboga recientemente por una psicología discursiva psicoanalítica, combinando dos elementos, la teoría de la acción del lenguaje de raíz wittgensteiniana, y una concepción dialógica revisada de la represión freudiana. También Jiménez Burillo (1993) rastreó la relación de vida y obra de Sigmund Freud con la socialización 
y la Ciencia política y en el momento de concluir señaló la contribución fundamental de este autor como la ilustración del conflicto primordial, y radical, entre biología y lenguaje. En conmemoración del 150 aniversario del nacimiento de Freud, Ovejero (2007, p. 62) concluye a partir de una intensa aproximación psicosocial al psicoanálisis que "estamos ante una teoría que nos ayuda a pensar en la pregunta central de la psicología: cómo hemos llegado a ser lo que somos".

Sin embargo, hemos de insistir en que la trayectoria constructiva de ambas tradiciones ha estado salpicada de cruces múltiples y variados, nunca definitivos, que reflejan tanto la dificultad para pensarlos conjuntamente cuanto la insistencia de su encuentro fallido. Miller (2000) reconoce que Freud partía de una perspectiva marcadamente biologicista, como un resto de iluminación ilustrada, del propio espíritu de su época. Se trata de un síntoma en sí mismo que Jacques Lacan, en esa operación que ha venido a denominarse "retorno a Freud", relanza, situando al psicoanálisis contemporáneo en la materialidad significante, más propia del lenguaje que de la biología (Lacan, 1984). Así la llamada teoría de la cultura freudiana descansa en la oposición cultura/naturaleza para ir más allá de la misma. La cultura en la producción freudiana se presenta como sinónimo de la desnaturalización: el ser humano por estar inmerso en un universo cultural está asimismo radicalmente separado de la naturaleza y su legado instintivo.

En este sentido, Alemán (1995) afirma que asumir las implicaciones derivadas de la práctica del psicoanálisis conlleva la reconstrucción de una categoría como la "naturaleza humana", especialmente en la relación con la especificidad de la satisfacción humana y sus rodeos y los avatares de nuestra sexualidad y del establecimiento de vínculos. Es desde estas coordenadas que pretendemos adentrarnos en la concepción freudiana de salud mental.

\section{La dicotomia cultura-naturaleza y la metáfora poder-expresión}

No es Freud, desde luego, el primer autor que considera al ser humano como un animal "no natural". Como nos recuerda Miller (2000) decir que el hombre es un animal político, o un animal que habla, es decir que en la humanidad la naturaleza ha sido reemplazada por la cultura. Pero la mayoría de los autores entiende en esta encrucijada que esta sustitución se realiza por la vía de la dominación de la cultura sobre la animalidad. Así existen recomendaciones filosóficas y de higiene social para que el humano vuelva a su origen natural, muchas veces identificado con una vivencia no restrictiva de la sexualidad, liberándose de las constricciones sociales y culturales. Esta confrontación entre naturaleza y sociedad estaría entonces en la base de los conflictos personales y 


\section{ARTIGOS}

sociales, generando un tránsito de retroalimentación continua para los mismos entre la esfera pública y la privada.

Pero es en esta disyunción donde Freud desestabiliza la relación antitética mantenida por la historia del pensamiento entre naturaleza y cultura y rechaza el ingenuismo del retorno a la naturalidad psíquica perdida del ser humano así como la mera consideración de lo social como agente represor de esa esencia natural. A este respecto, la obra de Freud es también amplia, compleja y diversa, articulada sobre múltiples aspectos de la vida psíquica y social, por lo que cualquier intento de resumirla o simplificarla puede desembocar en el simplismo o la distorsión. Desde textos tempranos podemos verificar una manera singular de aproximarse a la cultura, sus beneficios y perjuicios para la colectividad y los individuos singularmente considerados. Así Freud no habla exclusivamente de coacción sobre la naturaleza individual, no se conforma con esta concepción dualista. Le interesan igualmente otros mecanismos más íntimos que anudan esa divergencia a la propia constitución subjetiva del ser humano, atendiendo de manera especial a fenómenos de origen psíquico. En este punto se separa de otras tradiciones y prefiere el término represión psíquica (Verdängung), que es diferente cualitativamente del término que designa la represión social (Unterdrunkung). Freud supone la existencia de una censura, una barrera en nuestro sistema psíquico que le impide al contenido del inconsciente emerger al nivel de la conciencia. Este concepto de represión se arma sobre una base distinta de la coacción social, pues lo reprimido no es prohibido por alguna instancia exterior sino que es atraído al inconsciente y no precisamente para ser almacenado y finalmente olvidado puesto que retorna, se manifiesta de otra manera, mediante los sueños, lapsus y síntomas.

Partiendo de esta diferencia, algunos trabajos recientes de Alemán (2003, 2006, 2007) desarrollan la idea de que desde el punto de vista político el pensamiento de Freud representa un corte con la tradición. Durante siglos se había pensado el campo de la política desde la metáfora poder-expresión. Por un lado, en la escena política detectaríamos unas fuerzas en los sujetos históricos que según cada autor podían recibir nombres diferentes, pulsiones, energías, pasiones, inclinaciones etc., y por otro, un poder que, a través de la ley, tiende a coartarlas, controlarlas, para que el sujeto se vuelva susceptible de incluirse en el vínculo social. Freud comparte esta tradición como punto de partida pero introduce igualmente un elemento impolítico: una nueva complicidad entre la ley y la pulsión. A pesar de que nunca optó por un modelo político o colectivo en sus textos podemos encontrar algunas consideraciones preliminares para cualquier tratamiento de lo político (Alemán, 2006) que incluiría que:

- Todo vínculo social implica una renuncia al goce de la pulsión. 
- Esta renuncia la impone la sociedad a través de sus dispositivos disciplinarios, hoy más bien a través de dispositivos de control.

- Estos dispositivos de renuncia tienen carácter general y no toman en consideración la singularidad. La renuncia impuesta por la lógica del "para todos" deja siempre un resto pulsional no resuelto que se incrusta en los dispositivos simbólicos. Se puede convenir con Freud en que esta renuncia es injusta, pues está construida como lógica general y el supuesto beneficio se saldará siempre a título particular con la neurosis. La renuncia a través del imperativo categórico está mal construida pues se ha inventado como renuncia igual para todos sin tomar en consideración que esa renuncia tiene consecuencias diversas y distintas para cada uno.

- La renuncia que la cultura impone está contaminada por la pulsión que quiere ser dominada, ese resto infiltra la ley y el autismo pulsional se disfraza de ley para poder llevar a cabo su satisfacción paradójica.

Ya en un texto de 1908 "La moral sexual cultural y la nerviosidad moderna", Freud (1948a) aborda la relación existente entre los sacrificios y renuncias que nos son impuestas y el desarrollo de daños correlativos a la salud y energía vital que pueden poner en peligro incluso el propio fin social de los dictados de la moral cultural. Después de repasar las aportaciones de autores como von Ehrenfels, Erb o Binswanger, considera insuficiente el tratamiento teórico existente reducido generalmente a la influencia perjudicial de la cultura a través de la coerción nociva de la vida sexual de los pueblos civilizados por la moral sexual cultural imperante. Freud complementa la labor coercitiva de la cultura con la operación de renuncia, ligada también a una parte de las tendencias agresivas y vindicativas de nuestra personalidad, que será puesta al servicio de la común propiedad cultural. Freud achaca a la propia existencia humana y principalmente a los sentimientos familiares el protagonismo en la motivación de esta renuncia. Toma también en consideración la especificidad del instinto sexual humano, caracterizado frente al animal por su mayor desarrollo, su constancia y su capacidad de poder desplazar su fin sin perder grandemente en intensidad, otro fin ya no sexual, pero psíquicamente equivalente. Aquí reconoce, sin embargo, la presencia de "tenaces fijaciones" que en parte inutilizarían el instinto sexual humano para cualquier fin cultural, degenerándolo y condicionándolo a la expresión patológica. Tanto para la renuncia como para el desplazamiento, Freud insiste en tener en cuenta la diferencia de características individuales pues afirma que la experiencia enseña que para la mayoría de los hombres existe una frontera más allá de la cual no puede seguir su constitución las exigencias culturales. Todo aquel que quiera ser más noble de lo que su constitución le permita sucumbirá a la neurosis, se encontraría mejor si le hubiera sido posible ser peor. Así concluye que una de las más evidentes 


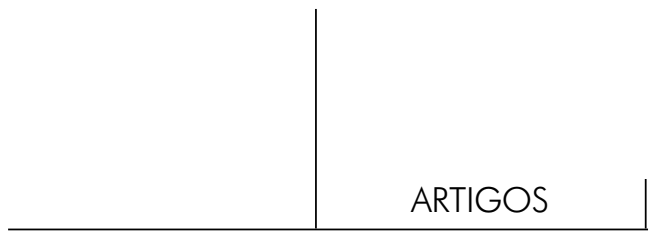

injusticias sociales es la de que el estándar cultural exija de todas las personas la misma respuesta.

\section{Cultura y clínica del superyó}

Es a partir del texto de 1920 "Más allá del principio del placer", con la evidencia de la compulsión a la repetición y el carácter conservador de la pulsión, que Freud (1948b) enfrenta a Eros (completamente en el sentido del Eros del Symposium platónico, tal como escribirá posteriormente en "El porqué de la guerra") un instinto (pulsión) antagónico, la pulsión de muerte, tendente a disolver lo que Eros promueve y a retornarlo a su estado más primitivo, inorgánico incluso. Se trata, como reconoce el propio Freud, de un instinto hipotético, cuya actividad no será tan fácil de demostrar pues actúa silenciosamente en lo más íntimo del ser vivo. Freud admite asimismo que una proporción de la pulsión de muerte podría ser orientada hacia el exterior, convirtiéndose en instinto destructor y en paradójico colaborador de Eros, pues el viviente dirigirá ese instinto hacia un objeto externo, en lugar de buscar la autodestrucción. Es en este sentido que Freud afirma que ambas categorías pulsionales no actúan de manera claramente diferenciada sino que generalmente se amalgaman entre sí, siendo imposible reconocer las acciones específicas de cada una, de modo que incluso "donde la destrucción aparece sin propósitos sexuales, aun en la más ciega furia destructiva, no se puede dejar de reconocer que su satisfacción se acompaña de extraordinario placer narcisista, pues ofrece al yo la realización de sus más arcaicos deseos de omnipotencia" (Freud, 1981, p. 3052).

Pero los límites a la agresión contra el exterior que son ofrecidos por la propia evolución cultural coartarán estas tendencias y las reenviarán al yo como fuerzas de autodestrucción. Para Freud, como estamos viendo, la cultura reposa en la renuncia a las pulsiones. Los métodos que la cultura usa para vincular a los miembros de la comunidad, que Freud (1948c) describe ampliamente en "Psicología de las masas y análisis del yo", apuntan a la identificación a los ideales y el establecimiento de vínculos amorosos coartados en sus fines, constituyen en sí mismos barreras a las tendencias agresivas amalgamadas al Eros. La masa, su formación y desarrollo, encuentra su fundamento en una ilusión, en los vínculos libidinales recíprocos entre los miembros y la figura del líder. La esencia de la psicología colectiva es el enamoramiento extendido a muchos y reiterado para cada uno como la multiplicación de la vinculación afectiva que converge en un mismo término. 
El resultado evidente es el poder apaciguador y unificante del Ideal. Pero aun así se presentifica un malestar en el proceso cultural que tiene su origen en el fracaso de este tipo de identificación simbólica para dar salida a lo que Freud llama "la paradoja de la ética", el problema del goce-en-más de la renuncia que se articula en su texto de 1930, y presenta a la conciencia moral como alimentada, sostenida por la propia satisfacción pulsional renunciada.

La cultura domina la potencial disposición agresiva del individuo, ligada al narcisismo y al propio desarrollo del yo, de manera que la agresión es introyectada, internalizada, devuelta, en definitiva, al lugar de donde procede, dirigiéndose al propio yo, constituyendo así lo que Freud llamará "superyó". Esta parte diferenciada se opondrá a la restante, asumiendo la función de "conciencia moral", desplegando sobre el yo la misma tendencia agresiva que éste podría demostrar con otros individuos ajenos a sí mismo, generando así una tensión entre estos dos componentes que será nominada "sentimiento de culpa", y que se manifiesta bajo la forma de necesidad de castigo. Aquí podemos detectar un nuevo viraje que otorga su peso específico a la aproximación freudiana frente a otras concepciones tradicionales de la ética y la psicología moral, pues para Freud no es necesario haber tenido contacto directo o potencial con la maldad para sentirse culpable, y busca un motivo distinto que finalmente sitúa en el desamparo y la dependencia estructural del individuo respecto del grupo humano (progenitores, familia, figuras de autoridad) y cuya consecuencia es el miedo a la pérdida de amor.

Freud habla también de una segunda fase en esta génesis en la que el superyó se comporta tanto más severa y desconfiadamente cuanto más cercano esté el individuo de la virtud, de modo que el propio sentimiento de culpabilidad es a partir de entonces heredero del temor al propio superyó. Se intensifica así el poder de la conciencia sobre él, impulsándolo al autocastigo, dado que ante el superyó no es posible ocultar la "persistencia de los deseos prohibidos" (Freud, 1981, p. 3056). Originalmente, entonces, la renuncia pulsional será consecuencia del temor a la autoridad externa (a la pérdida de su amor), y una vez cumplida esta renuncia quedarían saldadas las supuestas deudas. Pero en el caso de esta figura interiorizada que representa el superyó no basta con renunciar pues el deseo correspondiente persiste y no puede ser ocultado, por lo cual pese a la renuncia cumplida no dejará de surgir un fuerte sentimiento de culpabilidad, alimentando lo que Jacques Lacan llamará "voracidad del superyó". Todo ello representa, en palabras de Freud, una gran desventaja económica, en referencia a la economía libidinal, que acompaña a la instauración del superyó. El agalma entre instintos eróticos y de muerte se manifiesta en este caso en la erotización misma de la conciencia moral, lo que en terminología lacaniana podría expresarse como "gozar de la renuncia del goce" (Miller, 1991). La crueldad sádica del superyó nos

Rev. Latinoam. Psicopat. Fund., São Paulo, v. 15, n. 3, p. 497-511, setembro 2012 


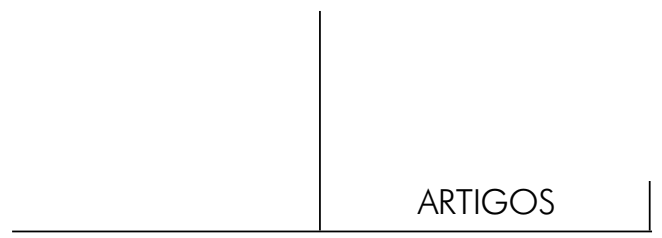

descubre que las exigencias de la moral tienen la misma fuerza que las pulsiones, tratándose sólo de un desplazamiento de las propias exigencias pulsionales. La elaboración freudiana refleja algo más que la simple oposición entre cultura y pulsión, y, como afirma Laurent (1996, p. 41), da cuenta de "una transposición más sutil en la que la pulsión alimenta la civilización y sus exigencias de renuncia encontrando, de ese modo, una satisfacción más secreta". El malestar en la cultura, por tanto, no procede tanto de las exigencias civilizadoras cuanto de la evidencia de que en éstas ésta directamente implicada la propia satisfacción superyóica. A esto es lo que se denomina, en general, pesimismo freudiano, pues la lectura optimista de la metáfora poder-expresión se queda fijada en la acción unilateral del poder sobre algo que queda imposibilitado de expresarse libremente. Freud encuentra en el propio sujeto un poderoso aliado del poder. La ley no es lo que pretende ser, este análisis le resta trascendencia, la muestra atada y sometida a algo que la ley quería esconder.

Estas son las claves para pensar la salud mental desde el malestar en la cultura. Freud (1981) en el capítulo VIII de "El malestar en la cultura" nos ofrece lo que él mismo llama la conclusión final de su investigación: el precio del progreso cultural debe pagarse con el déficit de felicidad. En este último capítulo introduce también el sentimiento de culpa al que hacíamos referencia anteriormente. Un sentimiento que puede mantenerse inconsciente, como algo indiferenciado, bajo la forma de malestar, de descontento difuso. Como hemos venido desarrollando, cuanto más y más renuncia un sujeto para satisfacer al superyó, más y más exige el superyó. El superyó está construido de tal manera que se convierte en un amo al que ninguna restricción pulsional puede satisfacer. Así una persona infeliz se castiga, se siente culpable, y pide perdón. La pérdida de la felicidad, en lugar de asegurarse el acuerdo del superyó, produce más infelicidad. Freud establece un paralelismo entre la cultura y el individuo, y eso nos da la posibilidad de convertir todo lo que en principio pueden parecer consideraciones sociológicas o antropológicas en consideraciones clínicas, y a la inversa. El malestar en la cultura es al mismo tiempo el malestar en el individuo y el malestar en el individuo aparece como el fundamento del malestar en la cultura. Freud no dejó explicitada cuál sería el tipo de civilización más adecuada para tratar el resto pulsional que se resiste y acaba vivificándose con la renuncia impuesta por la propia cultura. Formula, eso sí, en distintos textos, dos advertencias (Alemán, 2006):

- Una civilización que exige cada vez más renuncias pulsionales y no sabe ofrecer a los ciudadanos los medios sustitutivos para sublimar el goce imposible no merece perdurar. Aquí podemos intuir una crítica a la sociedad burguesa de su época no sólo por la acumulación de la plusvalía, explotando la fuerza de trabajo, 
sino por acaparar los medios de sublimación, fundando algo clave para la modernidad: el disfrute del arte como un bien en sí mismo.

- Cuanto más se exige a cada persona estar por encima de sus posibilidades en cuanto a renuncia pulsional más hipocresía e impostura impregnará el tejido social.

\section{Implicaciones para la salud mental}

Como vemos la dicotomía optimismo-pesimismo no está a la altura de la cuestión tal como la presenta Freud. Que la ley no es tan enemiga de la pulsión, que la ley no está depurada de la satisfacción patológica, tiene importantes efectos para la retórica de la liberación personal y política.

La salud mental queda subvertida por las posibilidades de invención que tiene cada sujeto para responder, por un lado, a las exigencias que la ley le impone, y, por otro, aquella parte de su experiencia vital que la ley nunca va a domesticar del todo, el resto pulsional que ningún sujeto logra civilizar del todo y con el que tendrá que convivir. Así Lacan, rechazando el cliché del psicoanálisis como terapéutica del psiquismo, entiende la experiencia psicoanalítica como la elucidación por parte del sujeto de ese resto, ese gozar-en-más donde de existir residiría la sustancia de lo humano. Como explicita Miller (1991) no se trata para el psicoanálisis de la salud mental al uso, definida por oposición a lo patológico desde el discurso médico. La propia concepción del término sujeto de la experiencia psicoanalítica, que aparece tempranamente en la obra de Lacan, impide pensar en un equilibrio con su naturaleza, una armonía estable con la realidad construida. A pesar de no constituir un elemento esencial del legado freudiano, Lacan lo sitúa como elemento central de su enseñanza a partir del fin de la Segunda Guerra Mundial, pues con anterioridad era empleado más bien para referirse al ser humano, en términos generales, o incluso al paciente en el dispositivo analítico. Lacan (1975) introduce la distinción entre el sujeto impersonal, independiente del otro, en el más puro sentido gramatical, el sujeto reciproco, sustituible por cualquier otro, que se reconoce a sí mismo en esta misma equivalencia, y el sujeto personal, acepción ésta que centrará su preocupación por el tema, sujeto cuya unicidad está constituida en un acto de autoafirmación singular. En la década de los cincuenta y a partir de la distinción freudiana entre das Ich y das Es, Lacan remarca la naturaleza simbólica de la entidad subjetiva frente al carácter imaginario del ego, en su núcleo constituido por toda una serie de identificaciones alienantes. Por tanto, la noción de sujeto no apunta sencillamente al concepto consciente de agencia; más aún, para Lacan el 
sujeto es el sujeto del inconsciente, y por ello sujeto de la enunciación, "capaz de juzgar él mismo lo hecho y lo dicho, en esto es un sujeto ético" (Miller, 1991, p. 72). A esto no es ajeno el papel primordial que Freud reserva al sentimiento de culpa, expresión patológica de la responsabilidad ética.

Aquí nos parece interesante la diferencia que plantea Jacques Lacan (1987) en su Libro XI del Seminario Los cuatro conceptos fundamentales del psicoanálisis entre resto y escoria. No es lo mismo reconocer que no estaré jamás incluido totalmente en la universalidad porque me considero particular, distinto, soy un resto que la lógica del "para-todos" ha dejado fuera para constituir el conjunto universal (el camino de dotarse de la propia singularidad en sentido heideggeriano), a considerar que el conjunto me ha abandonado como desperdicio, que no he sido merecedor de reunirme completamente en el conjunto, ser la escoria que ha caído de la operación de establecimiento del universal. Es en este punto donde podríamos hablar incluso de un optimismo duro, crudo, de la clínica del superyó al modo del existencialismo laico sartriano, un actuar sin esperanza, más allá del determinismo justificatorio y la "mala fe".

Pero, de qué depende que el sujeto se oriente por una u otra versión. En las páginas finales de "El yo y el ello", Freud (1978) parece dar una respuesta introduciendo el tema del amor. La única forma de dar la vuelta al malvivir es que se logre "un pacto de amor con el superyó" (Alemán, 2006), introducir el amor entre la pulsión y la exigencia. Se trata de un nuevo amor, una versión del superyó que ame al yo. Sin embargo, esta vía inaugura igualmente importantes tensiones teóricas, clínicas y éticas, que no han sido totalmente entendidas en todas sus consecuencias, pues la propuesta de Freud no es un amor al otro semejante, sino que habla más bien de una cuestión intrasubjetiva, centrándose en las condiciones en las que el sujeto pueda construir la relación con una ley más soportable, una ley que lo ame.

En este punto, Miller (2000) se pregunta qué produce el análisis, y la respuesta toma la forma de la rectificación, la transmutación subjetiva: la modificación de la relación con el superyó. Así el psicoanálisis da a luz sujetos que renunciaron a renunciar. Para ello no se trata simplemente de lograr una sociedad menos restrictiva y de adoptar una postura anti-institucional, sino, más bien, de ofrecer los medios para saber reconocer la paradójica relación entre la ley y la cultura. El malestar no se fundamenta en tal o cual déficit sino, más bien, en un exceso de carga por una satisfacción paradójica que no se deja reconocer. El problema ético no resiste ya las limitaciones del dilema renuncia-satisfacción: se trata de restaurar el deseo que hace vivir y no el impulsar la identificación con su goce vivido en el registro de la culpabilidad. La mala nueva del psicoanálisis será recibida, desde su nacimiento, de forma problemática. 


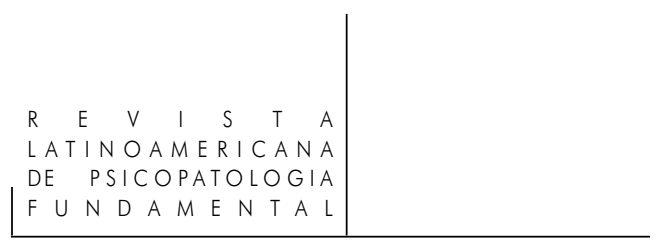

\section{Referências}

Alemán, J. Psicoanálisis y naturaleza humana. Archipiélago, Madrid, v. 4, p. 43-47, 1995.

Alemán, J. Derivas del discurso capitalista. Notas sobre psicoanálisis y política. Málaga: MGE, 2003.

Alemán, J. El porvenir del inconsciente. Buenos Aires: Grama Ediciones, 2006.

Alemán, J. El legado de Freud. In: Alemán, J. (Ed.). Lo real de Freud. Madrid: Círculo de Bellas Artes, 2007.

Billig, M. A psychoanalytic discursive psychology: from consciousness to unconsciousness. Discourse Studies, v. 8, n. 1, p. 17-24, 2006.

FREUD, S. (1908). La moral sexual cultural y la nerviosidad moderna. In: Obras Completas. Madrid: Biblioteca Nueva, 1948. v. I.

Freud, S. (1920). Más allá del principio del placer. In: Obras Completas. Madrid: Biblioteca Nueva. v. I.

Freud, S. (1921). Psicología de las masas y análisis del yo. In: Obras Completas. Madrid: Biblioteca Nueva. v. I.

Freud, S. (1923). El yo y el ello. In: Obras Completas. Buenos Aires: Amorrortu, 1978. v. XIX.

FreUd, S. (1930). El malestar en la cultura. In: Obras completas. Madrid: Biblioteca Nueva, 1981. v. III.

JimÉnez-Burillo, F. Freud y la política. Psicothema, Oviedo, v. 5, supl., p. 45-51, 1993.

LaCAN, J. El tiempo lógico y el aserto anticipado. In: Escritos. México: Siglo XXI, 1975. v. I.

LACAN, J. La cosa freudiana o el sentido del retorno a Freud en psicoanálisis. In:

Escritos. México: Siglo XXI, 1984. v. I.

LaCan, J. El seminario. Libro XI. Los cuatro conceptos fundamentales del psicoanálisis. Barcelona: Paidós, 1987.

Laurent, E. Siete problemas de lógica colectiva. Estudios Psicoanalíticos, Madrid, v. 3, p. 15-48, 1996.

Miller, J.A. Lógicas de la vida amorosa. Buenos Aires: Paidós, 1991.

Miller, J.A. El banquete de los analistas. Buenos Aires: Paidós, 2000.

Ovejero, A. Un aproximación a la psicología social desde el psicoanálisis: ¿es el psicoanálisis una ciencia, una mitología o una impostura? Encuentros en Psicología Social, Málaga, v. 4, p. 52-63, 2007.

Rev. Latinoam. Psicopat. Fund., São Paulo, v. 15, n. 3, p. 497-511, setembro 2012 


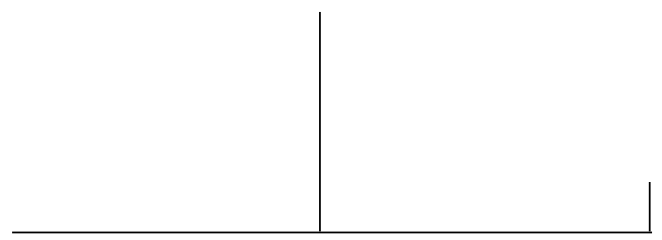

PARKer, I. Psicoanálisis y sociedad: subjetividad y psicología social. In: CorRea DE Jesús, N.; FigueroA, H.J.; LóPez, M.M. (Eds.). Coloquio Internacional sobre el Imaginario Social Contemporáneo. San Juan: Universidad de Puerto Rico, p. 31-40, 1991.

PARKER, I. El regreso de lo reprimido: complejos discursivos y el complejo-Psi. In: Gordo-LóPEZ, A.; Linaza, J.L. (Eds.). Psicología, discurso y pPoder: metodologías cualitativas, perspectivas críticas. Madrid: Visor, 1996. p. 253-68.

\section{Resumens}

(Pessimismo freudiano: saúde mental e o mal estar na civilização)

As relações entre a psicanálise e o pensamento social têm suas raízes nos primeiros passos da descoberta freudiana. O próprio Freud não é alheio a esta questão e após a Primeira Guerra Mundial dedica uma parte significativa de sua produção aos chamados textos sociológicos. Tanto a teoria social como o conceito de pulsão em suas últimas elaborações representam a bagagem mais comprometedora da herança freudiana, que somente alguns autores como Jacques Lacan estão dispostos a retomar. O chamado pessimismo freudiano associado a esses textos critica a leitura otimista da metáfora poder-expressão que estabelece a ação unilateral do poder sobre algo que fica impossibilitado de se expressar livremente. É a partir destas coordenadas que pretendemos adentrar na concepção freudiana de saúde mental. O fato de que a lei não seja tão inimiga da pulsão e que não está livre da satisfação patológica, terá efeitos importantes na retórica da liberação pessoal e política.

Palavras-chave: Freud, psicanálise, pessimismo freudiano, mal-estar na civilização

(Freudian pessimism: mental health e discontent in civilization)

The relations between psychoanalysis and social thought find their roots in the early developments of Freud's work. He took on this question and dedicated a considerable part of his production on the so-called sociological texts, published after the World War I. Social theory and his final conception of the drives represent the most compromising aspects of Freud's inheritance, to which only a few authors, such as Jacques Lacan, have been willing to return. Freud takes a pessimistic view in these texts and criticizes the optimistic reading of the metaphor of power-expression, which establishes the unilateral action of power on something that cannot be expressed freely. It is from these coordinates that the author of this article endeavors to update the Freudian conception of mental health and explore how the law is in a paradoxical relationshipwith the drives and with pathological satisfaction. This conception has important effects for the rhetoric of personal and political liberation.

Key words: Psychoanalysis, Freud, Freudian pessimism, civilization and its discontents 
(Le pessimisme freudien: santé mentale et malaise dans la culture)

Les rapports entre la psychanalyse et la pensée sociale remontent au début du développement de la découverte freudienne. Freud lui-même en est conscient et après la Première Guerre mondiale, il consacre une partie importante de sa production aux textes que certains appellent culturels. Autant la théorie sociale que la conception de pulsion représentent les bagages les plus compromettants de l'héritage freudien que seuls quelques auteurs comme Jacques Lacan sont prêts à reprendre. Le pessimisme freudien associé à ces textes critique la lecture optimiste de la métaphore puissance-expression qui établit l'action unilatérale de la puissance sur quelque chose qui est incapable de s'exprimer librement. C'est à partir de ces coordonnées que l'article sonde la conception freudienne de la santé mentale. Le fait que la loi n'est pas l'ennemie absolue de la pulsion et qu'elle n'est pas exemptée de la satisfaction pathologique produira d'importantes répercussions sur la rhétorique de la libération personnelle et politique.

Mots clés: Psychanalyse, Freud, pessimisme freudien, malaise dans la culture

(Freud'scher Pessimismus: Geistige Gesundheit und das Unbehagen in der Zivilisation)

Die Beziehungen zwischen der Psychoanalyse und dem sozialen Denken sind in den ersten Schritten der freudschen Entdeckungen verwurzelt. Freud selbst war sich dieser Frage bewusst und widmete nach dem ersten Weltkrieg einen großen Teil seiner Arbeit den sogenannten soziologischen Texten. Sowohl die soziale Theorie wie auch der Triebbegriff stellen in seinen letzten Schriften das verpflichtendste Wissen des freudschen Erbens dar, das nur einige Schriftsteller, wie Jacques Lacan, bereit sind erneut aufzunehmen. Der sogenannte freudsche Pessimismus in Zusammenhang mit diesen Texten kritisiert die optimistische Lektüre der Metapher Macht-Ausdruck, welche die einseitige Aktion der Macht über etwas, das sich nicht selbst frei ausdrücken kann festlegt. Von diesen Koordinaten ausgehend zielen wir darauf ab, die freudsche Auffassung von Geistesgesundheit zu untersuchen. Die Tatsache, dass das Gesetz nicht so feindlich gegenüber dem Trieb eingestellt ist und nicht frei von der pathologischen Zufriedenheit ist, wird bedeutsame Folgen für die Rhetorik der persönlichen und politischen Befreiung haben.

Schlüsselwörter: Freud, Psychoanalyse, freudscher Pessimismus, Unbehagen in der Zivilisation

Citação/Citation: Montalbán-Peregrin, F.M. Pesimismo freudiano: salud mental y malestar en la cultura. Revista Latinoamericana de Psicopatologia Fundamental, São Paulo, v. 15, n. 3, p. 497-511, set.2012.

Rev. Latinoam. Psicopat. Fund., São Paulo, v. 15, n. 3, p. 497-511, setembro 2012 


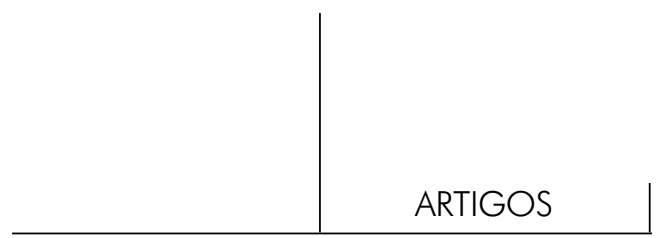

Editor do artigo/Editor: Prof. Dr. Manoel Tosta Berlinck

Recebido/Received: 4.5.2011 / 5.4.2011 Aceito/Accepted: 13.7.2011 / 7.13.2011

Copyright: () 2009 Associação Universitária de Pesquisa em Psicopatologia Fundamental/ University Association for Research in Fundamental Psychopathology. Este é um artigo de livre acesso, que permite uso irrestrito, distribuição e reprodução em qualquer meio, desde que o autor e a fonte sejam citados / This is an open-access article, which permits unrestricted use, distribution, and reproduction in any medium, provided the original author and source are credited.

Financiamento/Funding: $\mathrm{O}$ autor declara não ter sido financiado ou apoiado / The author has no support or funding to report.

Conflito de interesses/Conflict of interest: $\mathrm{O}$ autor declara que não há conflito de interesses / The author declares that has no conflict of interest.

\section{F. Manuel Montalbán-Peregrín}

Doctor en Psicología; Profesor Titular de Psicología; Facultad de Estudios Sociales y del Trabajo Universidad de Málaga, España; Psicoanalista; Miembro de la Asociación Mundial de Psicoanálisis.

Facultad de Estudios Sociales y del Trabajo

Ampliación del Campus de Teatinos, s.n.

29071 Málaga, España

E-mail: fmontalban@uma.es 